\title{
LETTERS
}

\section{Is it premature to SPRINT?}

Rabi and Padwal's ${ }^{1}$ thoughtful analysis of SPRINT ${ }^{2}$ raises two concerns.

First, SPRINT didn't really answer the question it purported to. It compared a strategy of maintaining systolic blood pressure below $120 \mathrm{~mm} \mathrm{Hg}$ against a strategy of maintaining blood pressure below $140 \mathrm{~mm} \mathrm{Hg}$. In fact, if a patient's blood pressure was 120-129 mm Hg, he or she would have either had their medication increased or decreased (depending on which arm of the study they were in). They would not have been congratulated for good blood pressure and left alone, as would likely happen outside of a study. If their blood pressure was 130-134 mm Hg, they would either have had their medication increased, or their blood pressure rechecked and medication decreased if their blood pressure stayed in the same range on their next visit.

Mortality appears to follow a U-shaped curve for blood pressure, whereby there is a "sweet spot," above and below which mortality increases. SPRINT showed that a target of less than $120 \mathrm{~mm} \mathrm{Hg}$ systolic blood pressure was statistically better than a target of $135-139 \mathrm{~mm} \mathrm{Hg}$, but the study did not look at what happens in the 120-134 $\mathrm{mm} \mathrm{Hg}$ range. Given that this may be the "sweet spot" for blood pressure, it is premature to conclude that the best target for blood pressure is below $120 \mathrm{~mm} \mathrm{Hg}$ systolic.

Second, Rabi and Padwal ${ }^{1}$ suggested that ACCORD $^{3}$ failed to reach the same findings because it was underpowered. I would suggest that if a study of almost 5000 high-risk patients with diabetes could not find a difference between the two strategies, perhaps the difference would not be considered very meaningful by most patients.

\section{David M. Allen MD}

Northern Ontario School of Medicine, Sudbury, Ont.

n Cite as: CMAJ 2017 February 6;189:E217. doi: $10.1503 / \mathrm{cmaj} .732448$

\section{Reference}

1. Rabi DM, Padwal R. Intensive lowering of blood pressure: Should we SPRINT? CMAJ 2016; 188:1067-8.

2. SPRINT Research Group; Wright JT Jr, Williamson JD, Whelton PK, et al. A randomized trial of intensive versus standard blood-pressure control. N Engl J Med 2015;373:2103-16.

3. ACCORD Study Group; Cushman WC, Evans GW, Byington RP, et al. Effects of intensive bloodpressure control in type 2 diabetes mellitus. N Engl J Med 2010;362:1575-85.

Competing interests: None declared. 